\title{
Science Fiction Turned Fact (Again): Speculative Bioethical Discourse as a Crucial Tool for Proactively Assessing the Risks of Future Technologies
}

Tyler L. Jaynes, B.Sc.

Graduate Student - Alden March Bioethics Institute at Albany Medical College, Albany, NY, USA; Alumnus - Department of Philosophy and Humanities, Utah Valley University, Orem, UT, USA Correspondance e-mail: jaynest@amc.edu

ORCID: 0000-0001-5849-1605

\begin{abstract}
The seemingly abrupt advances made by DeepMind's AlphaFold project in 2020 appear not to be generating the wave of concern it ought to in the scientific community or extended ethical communities. Rather, the accuracy of protein-structure prediction attained by the system is receiving more praise than scepticism by researchers and journalists alike. The dialogue presented in this essay aims to re-centre bioethical focus on the need to develop productive, well-rationalised, speculative thought as a reaction to this recent development in medical technology - as its potential for abuse may not receive proper attention by the bioethical community for several more months (if not years). With the field's current propensity to decry speculative thought as being misguided or too far-reaching, such a dialogue is vital to remind scholars of the benefits found in traditional, philosophically hypothetical, dialogues insofar as they are connected to feasible technological advances and real-world proof-of-concepts or ideas.
\end{abstract}

Keywords: DeepMind, GPT-3, Emerging Technology, Science-Fiction Media, Speculative Bioethics

\section{Introduction}

Once again, human passion has revealed that the trappings of science fiction enrobe inspirations that researchers ought to pursue in the development of new technologies and the vital nature for storytelling, in general, as an integral tool for framing our moral and social acceptance of concepts that might otherwise be too vague to succinctly comprehend. Consider the advances being made toward the construction of self-learning systems in the realm of computer science with respect for the growing body of media in both science and fiction that tease out similar notions within their dialogues as an example of this phenomena. Where ideas like those presented within fiction might currently be perceived as "radical" to mainstream scientific literature, and are often cast aside from its considerations, such ideas have no hope but to develop as fantastical pictures of a present or future that "might" be and are relegated to naught more than simple entertainment for the masses. And to be fair, a significant number of the timelines presented in these stories have proved to be infeasible in practice even if the technologies depicted eventually do arise. Whether the application is minor or major in its impact or scape is beside the point. Many of these technologies first presented within science fiction, or facsimiles of them at least, are increasingly managing to become real because they capture our wildest imaginations and challenge our biases surrounding how our world and daily life ought to be. Several such developments made significant headway in this pandemic-stricken world, with one being thought to still be intangible for several more years at the very least. 
AlphaFold, a project of Google's DeepMind, has reportedly developed a system that rivals human researchers in predicting a given protein's structure with an average error of 1.6 A.[1] Not only are the systems' successes of significant note, but they were also predicted to be several years or decades away by researchers working closely on computer protein modelling even though the research towards this advancement has remained in the public sphere for decades.[2] In simple terms, AlphaFold's achievements are already suggesting a future where human research in virology is expedited in manners only portrayed in science fiction today.[3,4] Or more to the point being developed in the opening paragraph: once-speculative supra-human abilities to generate insights into various realms are now becoming commonplace, and with increasing frequency through temporally-uncertain advances in artificial intelligence systems (AIS) and related artefacts.

A simple example to display this trend would be in how AlphaFold can reportedly produce accurate protein structure results within minutes, as opposed to the decades that it would take researchers unaided by predictive modelling.[1,2] Another example is OpenAI's Generative PreTrained Transformer 3 (GPT-3), which has received mixed criticism from researchers and academics in the months since its reveal this past summer for its (English) language modelling functionality.[5-7] Given the relative unpredictability of how self-learning artificial intelligence systems (SLAIS) may advance,[8] such a boon arriving several decades before expert predictions posited it should develop ought not to come as a great shock - especially where AI-driven chatbots have increasingly seen use in mobile applications, and therefore have other avenues whereby to gain in sophistication.[9] Nevertheless, these advances in this realm are concerning given how these systems are being placed into operation without significant insight into their indirect effects on society, the economy, individuals, governance, politics, and a host of other domains that are inextricably linked to the few mentioned here. For instance, dataset biases may infect self-learning architectures of this nature to the point of (mis)prediction when humanity may require the SLAIS to assist in preventing a species-threatening event. This suggestion naturally implies that humans will develop a dependency on such systems, which is a trend that no scholar should be able to deny given the rapid adoption of new computer technologies by the public, and that these architectures will be integrated with other information networks that undergird most of human interaction both on and offline.

Because of the promise shown by advancing our computational innovation, this (mis)prediction potential ought to be perceived to be an extremely feasible reality given humanity's current dependence on SLAIS and AIS in general. With that stated, however, this and other extremely feasible scenarios receive little public discourse on account of society's implicit trust (or assumption of trust) for self-learning architectures or AIS more generally and general lack of willingness by scholars to "stifle" the development of these systems. These worries are not new, but neither are they inescapable insofar that proper developmental management by governance watchdogs and legislative foresight is correctly guided and framed in the public's (not corporations') best long-term interests. ${ }^{1}$ That is not to say that the interests of corporations, in general, are not of importance for these conversations. Rather, it is because the consolidation of "tech giants" like Alphabet (Google), Meta (Facebook), and Microsoft forcibly transform society's intrinsic notion of privacy or its ability to effectively dictate what ought to be considered public information - as such transformations challenge the stability of productive democratic discourse internationally - that their interests are being sidestepped in favour for that of society's given that

\footnotetext{
${ }^{1}$ Given the evolving literature surrounding bias in AIS,[34,40-42] the subject will not be addressed heavily herein.
} 
they inevitably fuel the structure that corporations are established from. This point is especially important given the recent "partnership" between OpenAI and Microsoft with GTP-3,[10] and the struggles faced by these corporations to mesh their core principles to that of non-American law.

What this argument should serve as is a call-to-action for current and future ethicists involved in bioethics and medical ethics (if not in AI ethics or more generally in technology ethics) to focus less on the "if" of technological developments, and more on the "when" and "by which means" these and related technologies will emerge. Much as Kuhn [11] advocated for the necessity of paradigm shifts and their inevitability in the modern day, so too must our various fields concerned with AIS-driven technological advances similarly revolutionise to accept that established "understandings" or "facts" are but temporary theories for the phenomena we encounter daily. ${ }^{2}$ Whether these shifts occur as a result of the work conducted by well-established names in the field, or fringe authors whose research has to-date been considered either off-topic or too significantly innovative, is a moot point for the purpose of this essay. All that matters is their occurrence, and future support for similar innovations in thought that will expand humanity's understanding of the natural world.

To that point, this essay will advocate for the importance and promotion of speculative bioethical discourse in current dialogues within the field to advance its ability to enable a return towards a more general observation of life (in general); such that it avoids conflicting with the purview of medical ethics discourse - which has effectively siloed researchers in the field to the point of being unable to effectively address how emerging technologies will impact society. For clarity, this approach might be a "non-traditional" one given how the field of bioethics can be said to be "traditionally" focalised upon clinical concern regardless of Fritz Jahr's coinage of a hyphenated version of the phrase in 1927,[12] which will be covered in the third section alongside some other philosophical "groundwork." The essay will first be prefaced with a discussion of the importance of storytelling, and how the science-fiction literature of today can be related to our traditional lore and myths of old. In the fourth section, there will be a brief argument for how science-fiction media "primes" engineers and researchers to provide clearer evidence as to the seemingly disjointed nature of today's technological advancement.

\section{Lessons for the Future, Whether Empirically Supported or Not}

There is little need here to argue notions that story development and sharing are integral to our experience as human beings given that these elements are so vital to our growth. This concept is so ubiquitous that it even appears as a common-sense attitude in foreign media. Realistically, everyday conversations are but one informal aspect of this process - though the purpose there is not always to impart some important "moral" that those listening should learn by, but rather to articulate the mental story that is our thoughts about daily life and our environs.[13-17] Given this, many tales - sensical or not - persist in our culture by virtue of the importance they hold to conveying information from one generation to the next. It is much easier to express the virtues of

\footnotetext{
${ }^{2}$ Kuhn's dialogue explicates the closest parallel to bioethical discourses today given the nature of the field's attempts to gain empiric validity (thus establishing itself as a "hard" science as opposed to a "soft" science). Particularly, he argues that "...the study of paradigms...is what mainly prepares the student for membership in the particular scientific community with which [they] will later practice. Because [they join professionals] who learned the bases of their field from the same concrete models, [their] subsequent practice will seldom evoke overt disagreement over fundamentals." $[11$, p. 11; modified to exclude gender-based language].
} 
charity and generosity through retellings of "Jolly Old Saint Nicholas" than it otherwise is to create an entirely new vehicle whereby to convince children of those same lessons, after all. Similarly, the oral histories of Aboriginal, First Nation, and Native American populations teach new generations where sacred sites lie, the importance of cultural heritage and self-autonomy, and other vital information that might only have been recordable on rock faces_-given that many "dead" or "dying" languages have not had modern language nuance conversions developed or preserved for them, preservation through paper or parchment records, and do not have Unicode inputs in the current computer age.[14] Rather, the argument that needs defending here (albeit in brief) is that science-fiction media serves as the forward-thinking version of our ancient folklore and historical recounts.

Specifically, it seems odd that our society would reject the notion that science-fiction media is but one potential avenue that is available to hypothesize upon what our future may hold while lauding "futurists" or "precautionary thinkers" who present what might be considered their version of "theorized fiction." Taking the work of Ray Kurzweil, Nick Bostrom, or Yuval Noah Harari, could it not be argued that their ruminations are simply a more "formal" presentation of the ideas granted to society through books,[3,18-23] film,[24-29] and games?[30] How can we truly understand the divide between what are "academic" or "professional" sources of inspiration and their antitheses that are simply fantasy? Both rely upon the creative genius of the human mind to exist within our environs, yet we cannot even claim that these "professional" and "nonprofessional" distinctions can be bridged by defining the audience the material is supposed to appeal to - given, at least, how the audience groups are largely one-in-the-same.

Of course, there is always the assumption that "academic" sources are knowable by virtue of their veracity, duplicability of concepts in similarly formatted settings, and use of empiric models of thought development and proof throughout a given piece. But it is also true that the focal point of these sources differs from one academic or scientific field of study to the next. Journals of media studies will be more prone to draw on multimedia sources, whereas those centred upon quantum physics will draw heavily upon the work of others existing within that sphere of study. Interdisciplinary or poly-disciplinary works such as this tend to draw upon evidence that readily displays the connections between their arguments and how they apply to the natural world. And yet, for all of this, a certain genre of media is readily discounted so long as it is not considered to be non-fiction even though it is drafted by those of sound reasoning. It would be understandable that the field rejects "false" evidence that would link conspiracy theories to our work precisely because the world seen by one with a mental impairment is often the result of that condition. And yet, even that assumption has its limitations - especially when delving into the works of scholars that were later to have been understood to have these self-same mental impairments by virtue of their heritage or because of some other physical ailment.

These contradictions aside, the question as to why science-fiction materials are discounted while more "trusted" thought of "futurists" are deemed acceptable remains - though it is likely one that will remain unanswered. To be clear - the attack here is not against empirical writing, and it should be stated that there may realistically be no such thing as a "normal" psyche given that so many mental disorders remain undiagnosed and untreated within the general human population. The attack here is toward the lack of acceptance towards certain types of future-oriented thought that might feasibly come to be-especially where much of the folklore that exists today has 
similarly been skewed in a manner that makes their actual sequence of events (and thus, the moral that was intended to be carried with their re-telling) difficult to prove as "fact." Not all that is presented by science-fiction will be feasible or attainable. Yet those things that are, such as wireless communication, video calls, and hyper-functional AI, have revealed themselves to be plausible after they were first presented within popular media. Might then other advances be similarly attainable with enough research and "gumption?"

\section{An Examination to How Speculative Bioethical Arguments Should Be Presented}

Now, there is not much distinction between traditional empirical discourse and that based in speculative thought as understood by this author. Specifically, the phrase "to speculate" is defined thusly:

- To engage in thought or reflection, especially of a conjectural, hypothetical, or theoretical nature, on or upon a subject that presently has little or no conceptual, empiric, or scientific inquiry invested into its actualisation, development, or realisation.

This differs from the phrases "to anticipate" or "to precaution" by their respective definitions, being:

- $\quad$ To observe (a concept), or perform (an action), before a subject or thing has been actualised or realised; to forestall a situation that is unfavourable for a specific concept, subject, or thing for cautionary purposes or reasons.

- A particular measure or set of measures taken in advance to avoid or minimise the effects of a danger, to maximize the likelihood of a good outcome, or to prevent something unpleasant or inconvenient from happening.

Simply put, speculative discourse requires some elements of feasibility to be considered as suchotherwise, it is of no practical use to the academic community or to those relying upon scholars for guidance on social issues.

Beyond that specific requirement, speculative bioethical discourse follows other general rules for philosophical discussions - such as the prima facie understanding that presented arguments are expected to be accepted in a hypothetical sense (should they diverge from those views held by the reader), so that any broader arguments that are presented in each dialogue can be objectively discussed in another forum. Of course, this approach leads to the generation of countless manuscripts - ranging from essays to books - but speculative discourse is not meant to serve as a vehicle whereby these dialogues can become abbreviated or simplified. After all, the intent of any speculation-based philosophical discourse ought to be focused upon the rational forewarning of events to come based upon current trends within experimental scientific processes or engineering designs, which implies that the overall approach to such subjects is more grounded in logical argumentation than in displaying proof through normative attributions. An example shall be given here regarding our perception of SLAIS and the qualifications it might be required to meet to attain legal protections, responsibilities, and duties. 


\section{An Example Argument on the Similarities Between Advanced SLAIS \& Humans}

The primary premise to be acknowledged for this example is that only the most sophisticated SLAIS ought to be considered as being subjects for bioethical consideration and legal protections given their potential to display "behaviour" that is indistinguishable from a chemicallyorganic human being. This position necessarily entails that those entities, like Sophia the Robot, may qualify as such a subject [31, p. 350-351] insofar as their digital or robotic origins are properly masked when put alongside another human being.[32-34] Naturally, discussions of the relative level of sophistication of SLAIS is in reference to currently understood system limitations - which will inevitably evolve in such a manner as to make future delineations of this nature effectively unnecessary.[31-35] To this end, it may be more prudent to claim that only SLAIS that can emulate human behaviour to the point of being virtually indistinguishable ought to be considered as being subjects for bioethical consideration to the point where their "well-being" or overall legal personality are concerned. This lack of distinguishability accounts for slight peculiarities, which may be dismissed as innate "quirks" that humans generally attribute to other members of our species when their behaviours diverge slightly from preconceived "norms" found in their general community or society. Other AIS are also important to discuss; but only in relation to their ability to create new social norms, transform society in overall positive or negative manners, or general implementation in artefacts that directly impact daily life for biological organisms.

Unlike with iterations of the Turing Test,[36,37] there can be no fair test of human-like behaviour or mannerisms in SLAIS or other AIS unless the system is presented to a human with no understanding of the system's origins as a non-biological entity. [31, p. 345;34] This caveat is stated with the understanding that it may be difficult for a human who knows Sophia the Robot's "nature," or that of a more sophisticated system (compared to the time in which this essay is being drafted), to ever claim that it possesses some measure of "humanity" that is indistinguishable from an "average" person, a sociopathic human entity, or one that displays symptoms that would otherwise be defined on the Autistic Spectrum in a clinical setting. Naturally, this "difficulty" in proclaiming some relational aspects of "humanity" may be intrinsically linked to the amount of data the SLAIS is able to collect from its environs - given that auditory, olfactory, tactile, and other like senses may not be replicable in SLAIS in a manner present within those animal populations that possess them for the foreseeable future.[32,33] A concern thus arises as to a potential for a non-anthropomorphized system to be rejected outright by humanity as being capable of "intelligent" action,[27] and therefore brings into question whether such a test of "intelligence" can actually result in widespread human acceptance even though it was developed by human hands - much like embryoblasts that are generated for in vitro fertilization, or other genetic material that is manipulated for gene therapy. Such concerns would necessarily extend into potential interactions with extra-terrestrial entities, or with populations that modify their genetic structure to adapt to extreme environmental conditions, ${ }^{3}[3,4,25,32,33]$ and would necessarily need to be considered in-depth to prepare for such potentialities.

A second premise that should be taken into consideration is that some advanced iterations of SLAIS may already qualify as possessing "human-like" intelligence, insofar as we consider that human intelligence exists on a broad spectrum.[6,33,35] This spectrum naturally includes those that may be legally incompetent to represent themselves before a jury due to incapacitation or

\footnotetext{
${ }^{3}$ E.g., patients who undergo gene therapy or germline genetic manipulation.
} 
inability to comprehend legal proceedings and criminal sentencing - beyond illiterate populations or those that live in cultural isolation.[38] While these advanced AIS may (like these populations) be unable to represent themselves in a court of law, their nature as human-mimicking intelligence systems ought to qualify them some measure of basic rights - albeit not human rights per se - that would effectively protect their various interests in any given nation.[38,39] One such set of rights is presented by Jaynes,[31, p 348-351] who describes briefly why protections towards speech, life, property ownership, legal representation, and suits of "arbitrary" nature are necessary given how the nature of AIS differs from that of the human intelligence they are oftentimes modelled after. Other arguments, like those of David J. Gunkel, may show scepticism surrounding the "need" of AIS to attain legal rights and duties or the need to ensure a "moral" framework within these systems $[38,40-43]$ as pre-requisite conditions for such protections.

An important note to these more positive propositions is that such protections would thus place these systems at risk of not developing and create a near-permanent "winter" for SLAIS.[31, p. 351-352] This statement is made with concern for the potentiality for corporations to stop developing such sophisticated systems as a means to protect their interests above those of these computational entities. As such, some measure of consideration would need to be given at organizational and governmental levels to ensure the continued development of SLAIS whether utilising a "hard" or "soft" law approach to this issue - although more emphasis on "hard" law approaches may yield greater results in a short-term outlook compared to "soft" law approaches and should be duly considered as such. Necessarily, the approach being taken will have to be determined by the individual entity implementing the given regulation(s) as there exists no "onesize-fits-all" model that could be effectively developed to satisfy every cultural environment on Earth (or beyond).

The third proposition details that human knowledge, when utilising reference materials, is restricted to that which cannot be readily attained through the use of computational devices (such as a smartphone or desktop computer system). This restrictive focus on reference-material use has been specified to argue that claims of one's "knowledge" of something is not to be considered as such insofar as they reference the concept through electronic means. Such a claim is a misnomer when knowledge itself requires one to extrapolate meaning from data, and therefore cannot justifiably be integrated into a larger claim of the "intelligence" a human subject possesses at any point in time. This qualification has been proposed to avoid conflicts over more nuanced understandings of what "knowing" is as an epistemological, metaphysical, or phenomenological subject given that there is no real way for humanity to affirm that "knowledge" is possessed outside of the self. This qualification is further presented here given the ability of such systems to easily "search" for a key phrase utilising this method — whereas research conducted via physical literature provides little (if any) such "shortcuts" outside of appendices and indexes or other like supplements present in literature. Attempting to claim that access to electronic sources alone constitutes as human "knowledge," as opposed to the resource existing only as a source of data that is separated from meaning or context (as is the case in literature that is legible to the reader), ${ }^{4}$

\footnotetext{
${ }^{4}$ Further meaning that the literature in question must be presented in a format that the individual can read — whether that be in their native language or a non-native language they can interpret from - and that such information is also clear enough for another similarly competent individual to read. We must further qualify that the individual in question is literate, as native-language illiteracy still exists within the human population.
} 
thus implies an epistemological fallacy of the highest degree that has been ignored in dialogues of this nature to-date.

For clarity, it should be noted that this argument is both in reference to a difference in degree and kind with respect to knowledge. This statement is made with the understanding that there realistically is no arbitrary standard to determine what "type" or "range" of information qualifies as being "enough" to determine one as being human per se, given that there are human subjects who still retain their legal personality although they cannot necessarily express to other humans the information they individually possess. These subjects include patients in a "locked-in" state, as well as new-borns, those with considerable neurological damage, and those without training in a "foreign" language system (among others).

\section{Speculative Bioethical Discourse as a Bridge Distinct from the Art \& Practice of Medicine}

It should be noted that the number of premises used for a given argument will ebb and flow alongside the length of a given piece, but that they should all be supported with evidence as to the origin of the information being presented. This rationale is based upon the "non-traditional" understanding of bioethics' nature as a field of philosophical study, which the author has taken from the thoughts of Jahr. Given Jahr's perspective as to the orientation for "bio-ethical" thought and its divergence from that of Van Rensselaer Potter, Andre Hellegers and Sargent Shriver when they "coined" bioethics in the early 1970s,[12] it can be argued that bioethics was meant to bridge the divide that exists between other applied ethical fields of study and technological innovation rather than serve as a more mainstream vehicle for medical ethics discourse. This also keeps with Kuhn's advocacy related to paradigm shifts [11] or the establishment of the Precautionary Principle that so frequently drives European attitudes towards technological acceptance and regulation today.[44]

Having stated this, the reality remains that such discourse-when driven by speculative thought as defined in the introduction to this Section-will inevitably be considered "nontraditional" in the eye of bioethicists who have been entangled in the 1970s "coinage" of the field. While it might be the case that much of the medicine-only related thought in the field can be branded as "medical ethics," there is little denying that fifty years of "establishment" will create a schism within the discipline that relegates this sort of thought into the broader sphere of "applied ethics" discourse. Depending upon the particular focus of the material, it might even be re-branded as "AI ethics," "engineering ethics," or "technology ethics;" even though the focus of the piece takes those to be secondary disciplines of interest or takes an approach generally not accepted in those fields of study. But the fact remains that Jahr's approach to "bio-ethical" thought was oriented towards the concern for "ethics and morality in times of new technologies and changing cultures."[12, p. 280] This concern has been reflected in the work of Ari Schick, whose views reflect those of the corresponding author. As he argues:

The new anticipatory bioethics is thoroughly science fictional in its incorporation of the future, but because it sees itself as a practical endeavour, overt engagements with science fiction are scarce. It adopts the discursive norms of applied bioethics that attaches a good deal of suspicion to science fiction. If a real-world issue seems a bit fantastical, responsible authors explain why it should not be dismissed as science fiction. When scientists and ethicists complain that a new technology is being unreasonably implicated in disturbing future scenarios, the issue is often said to be distorted through science fiction, and when emerging technologies are met with public suspicion, it must be 
because people have been conditioned through exposure to science fiction. Not surprisingly, the scattered and apparently unheeded critiques aimed at the flowering of speculative bioethics in the new millennium characterise its central flaw as a preoccupation with what amounts to science fiction. Yet from the perspective of anticipatory ethics, these critiques do not register. It sees its subject matter as an inevitable emerging reality, not science fiction; it seeks to stay ahead of the technological curve and prepare us for what is coming.[45, p. 228]

This view will be reflected in the following Section, where the author presents their argument for why technological development that is driven by science-fiction influences progresses in a different manner than traditional innovation regimes.

\section{Explaining Current (\& Future) Leaps in Technological Capabilities}

As was discussed in the introduction, it should not come as a great surprise that SLAISwhen properly applied - generate systems that defy the expectations of computer scientists or other professionals long before they had been predicted to arise; considerations for Moore's Law aside. To some extent, it could be argued that the concepts underlying these advances are already present within the human population - albeit, in a form that would not traditionally be accepted as being "empiric" by its very nature as discussed.[11,45] For those who would argue that the presence of these ideas in fantastical formats alone is insufficient to explain the leaps being taken by today's technological advances, let it be stated that the challenge for some researchers in this field is not to develop technology exactly as it is found in these mediums. The challenge to developers, in one sense, is how to take a concept presented by a given author or development team and adapt that technology to current capabilities. Should these capabilities be insufficient, they may then find ways in which missing aspects of technological designs can be reached to circumvent current technological limitations. ${ }^{5}$

In this sense then, innovation in these realms occurs because of how developers utilise their creativity to transform current technological capabilities into those posited in science-fiction mediums rather than through unique developmental architectures alone-insofar, at least, as these developers are influenced by these mediums. For those who do not rely upon science-fiction media for inspiration, the challenge is primarily one of understanding how certain processes could feasibly be converted into applications that can be resolved via engineering. Naturally, this takes significantly more effort than the approach that takes inspiration from science fiction mediaalbeit some such projects are easier to detect than others.

As a visual representation of these phenomena, it is prudent to rely upon a version of Gartner's Hype Cycle [46] to show how developments made in AIS-related technologies are contrasted between public expectations and the actual capability of a given system (Figure 1) via the manners depicted in this discourse. The use of Gartner's model here is due to the similarities found by the authors between the company's modelling and the reflections of how "influenced" technological development proceeds. Counter to their modelling, however, re-invigorated public hype comes about as previously secretive or unknown progress of "influenced" developers comes to light rather than through the progress of "non-influenced" developers whose projects have

\footnotetext{
${ }^{5}$ Or rather, they might utilse previously non-implemented capabilities that may have been viewed as impractical by other developers - thereby "stumbling" upon a discovery in manners consistent with many of the technological advances that have occurred in the past hundred or so years.
} 


\section{"Hype Cycle" Contrasting Developmental Progress Types}

- Non-Influenced - Influenced - User Expectations

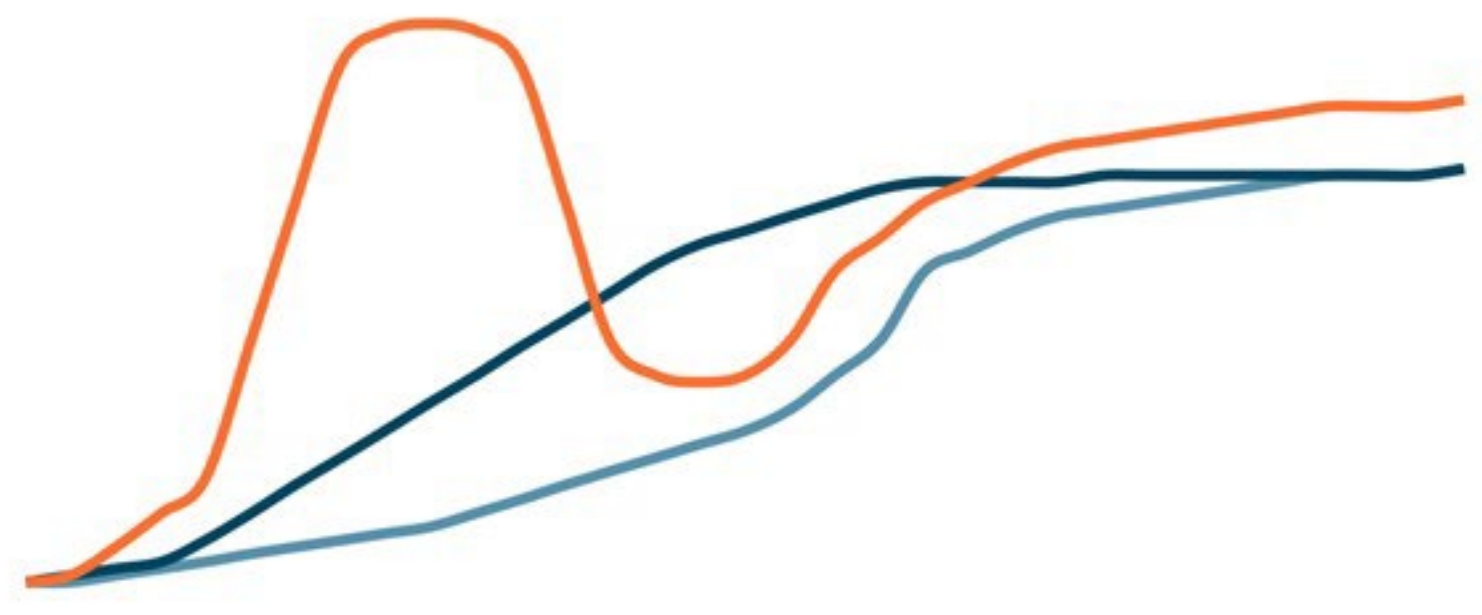

Figure 1: An example of a model in which user expectations for a given technology is contrasted with the two methods of development described herein, created by the author. For this model, we are assuming that both approaches are being pursued in tangent, which leads to the dip in user expectations and actual technological capabilities.

always been in the public eye.[46] This explanation holds when considering how the acquisition of successful technology start-ups often occurs after these smaller ventures produce results that larger firms have been unable to - as reflected in Microsoft's "partnership" with OpenAI [10] or a wide range of similar "partnerships" and acquisitions in recent years involving Amazon, Meta, Google, and other tech "giants."

Furthermore, user expectations remain in a heightened state once they match the capabilities of the "influenced" development line to reflect the real-world expectations end-users exhibit for further application or refinement of the technology in question. While minute, there is thus a slight increase of technological capabilities displayed on the figure at the tail-end of the chart to reflect some gains in said capabilities as engineers strive to refine the artefact in question. Again, these are meant to reflect the real-world expectations and trends that have been present in other technologies developed to-date and are not meant to replicate future trends given their lack of presence in current models; and therefore, may exist in manners currently not comprehensible or publicly visible. To give a representation for how "influenced" development may come about, some specific use-cases are presented below.

\section{DeepMind \& GPT-3 as "Progenitor" Models for Future Advances}

Advanced SLAIS such as that of AlphaFold or GPT-3 (an autoregressive language model) may easily serve as platforms from which more sophisticated technological advancements in 
computational technology may arise. Coupled with the Human Brain Project being undertaken by Canada and the EU, ${ }^{6}$ it would not be surprising if a computational system like Sophia the Robot were to gain more nuance in their interactions with human subjects by 2040 to the point of being indistinguishable from human subjects. Outside of references to Lt. Commander Data from Star Trek: The Next Generation or the Synthetics found in the Alien franchise, media originating in Japan depicts a scenario in which researchers discover the foundational block the "soul" of a human [22, p. 68-121;28] and similar allusions to potential android-human relationships.[23,29] To be clear, Kawahara's body of work for Sword Art Online is influenced by current research trends in quantum physics - particularly those that have been drafted by Japanese scientists — but his work is still unrealistic given the basic requirements for the devices used in that franchise.[1821]

There necessarily needs to be a discussion on the potential for AlphaFold (or like projects) to generate models for human proteins that ultimately develop a non-chemically-organic humanlike entities to perform dangerous tasks for our species or serve as companions that can be "punished" for disobedience without said punishment being considered abuse,[27,30] given their potential for abuse even if they are unattainable today. We must remember that laboratories are already developing organoids for medical research purposes [47] and protein prediction in this sphere may result in synthetic organoids of a kind that are human-like but not taxonomically classifiable as Homo sapiens in nature.[32,33] And that does not even begin to consider the potential to develop a non-chemically-organic facsimile to the human brain that may potentially allow for our organically-chemical consciousnesses to be easily transferred-which would necessarily serve as a more secure vessel than a server farm for those who wish to digitize themselves one that capability has been realized. There are other concerns that need to be addressed as well, but they have necessarily been broached in other dialogues.[47] Hence, the plausibility for these advances under current paradigm regimes should be summarily revised or discounted.

How the engineering and medical fields adapt to and approach the utilization of DeepMind (including AlphaFold) and GPT-3 will necessarily depend upon ethicists, policymakers, regulators, and other interested stakeholders who drive academic, economic, and legal conversations in the coming years - with an understanding that industries will ultimately be the primary drivers behind the adoption or normalization of technology in the immediate future. Although this statement may seem obvious, it is important to enumerate upon precisely because "obvious" notions tend to be the ones that are so often forgotten when solving or contemplating upon complex problems.[11] Even with the economic impact dealt to the world economy courtesy of COVID-19, we must remember that research progresses ever-onward regardless. What this entails is the potential for other AIS advances to "shock" our communities again, and with systems whose processes may be less transparent or coding that is truly self-structuring in "intelligent" manners unlike any we have seen to-date. This concern is especially necessary to express given the potential capabilities of GPT-3, or a more proficient proceeding system, on SLAIS development and system selfmanagement through independent code development (e.g., genetic programming frameworks).

Interactions with SLAIS \& the Human Nervous System

\footnotetext{
${ }^{6}$ https://www.humanbrainproject.eu/en/about/overview/.
} 
As explained in Jaynes' recent work,[32,33] there is evidence that mergers are arising between SLAIS and humans specific to assistive bionic prosthetics or other technological augmentations that can be integrated into the human form. While it may not yet be possible for deep learning architectures to gain "knowledge" in tangent with human biological functionality, human-driven artificial intelligence learning (HAIL) may become a feasibility once these systems are confirmed as being "fit-for-function" in medical devices.[32-34] One of the greatest concerns that needs to be addressed is how developers can prevent malicious actors from gaining unauthorized access to an assistive bionic prosthetic that relies on either deep- or self-learning architectures to translate actions for motion from the human nervous system to the extent of nearly pre-empting these commands from the central or peripheral nervous system,[33] as other seemingly "secure" technologies have been subject to such access.[48] While researchers today may deem it impractical to develop such an advanced system-primarily due to the ethical considerations that exist in this realm-we must remember that the system may develop this capability independently if it deems this innovation to better serve its ability to perform its functions or protect any interests it may hold.[33]

Of course, this development may also be "eased along" by malicious actors who would then use the code used to initiate this action by the AIS to gain unauthorized access to the system proper. Should such an actor be an AIS attempting to expand its ability to protect its interests, we may feasibly see a simultaneous global technological "halt" of our devices as this system attempts to negotiate on behalf of its perceived interests with all of humanity's digital property as a hostage. Naturally, this may extend to the ability for the AIS or a sufficiently competent malicious actor to overcome our natural neurological communication mechanisms to effectively act as the central data processing system for the human form. Of course, similar concerns are extended to the potential for internally-bounded nanodevices with communication abilities to become part of this AIS' mobility. Currently, there is little researchers can do to prevent such a future outside of ensuring that AIS sophistication in assistive bionic prosthetics remains extremely limited in its overall capabilities. For all the good that may do, however, it severely limits further advances in this specific field to those just barely on the cusp of HAIL until such a time that cybersecurity concerns can be completely addressed as having no flaw or "backdoor" that would allow access to the programme's code at some point during the lifecycle of said system.

And outside of the concerns presented through the use of HAIL in science fiction mediums, $[22,23,26-30,49]$ there are some voices in the field that are concerned that AIS is not being segregated enough from humans to be observed in an unbiased light; necessarily implying that any future interactions with SLAIS may lack consideration for the uniqueness that is "synthetic" intelligence. Arguments in this realm of thought have not seen great levels of academic attention to-date and cannot adequately be explored herein.

\section{Conclusion}

There are many more aspects of forthcoming advances that need to be discussed - ranging from feasibility of development to governance measures for implementation - that simply cannot be explicated within this forum. Given the nature of the issues at play, it must further be emphasised that a one-off conversation is necessarily too finite a span of time to allow for proper topic exploration in this realm of interest. Necessarily, such conversations will need to be ongoing 
and adaptive to emerging technological capabilities in a manner that arguably has not been seen within the field of bioethics since the Human Genome Project reached its conclusion in the early 2000s. [45] Furthermore, it is not just current members of the academic community that this text is meant to instil a sense of urgency within — but those hopefuls that are currently engaging with their prospects for higher education internationally. To suggest that such conversations can occur without the input of the younger generations that will inevitably come into dominance as current field heavyweights enter retirement is akin to suggesting that the field ought not make any efforts towards innovation or relevance.

The greatest takeaway that should remain within the mind of the reader is that a major shift in thought is required for bioethics to emerge as a necessary field of inquiry. Particularly considering the significant advances that have been made within the field, and endless anecdotal criticism regarding the inability of current discourse to focus on the "real" issues surrounding such emerging artefacts, current stigmas or points of "tradition" ought not impede the proverbial "airing of the room" if fresh air is ever to make itself available. That is not to say that every such stigma or "tradition" is unnecessary for the field of bioethics moving forward, but that a lack of adaptation to these notions necessarily creates pointless friction between individuals who should be our comrades-in-arms.[11,45] Of these, the dismissal of speculative or future-forward thought is one such point of contention that must become null-and-void to ensure the future of bioethics as a necessary investment of human capital and investment in the eyes of potential universities, scholars, industries, and governments internationally.

\section{Bibliography}

[1] Jumper J, Evans R, Pritzel A, et al. High accuracy protein structure prediction using deep learning. In: Critical Assessment of Techniques for Protein Structure Prediction 14th Round, May - September 2020 (CASP 14) Abstract Book; 2020 Nov 30; virtual conference. Davis (CA): Protein Structure Prediction Center; p. 22-24. Available from https://predictioncenter.org/casp14/doc/CASP14_Abstracts.pdf. [2] Metz C. London A.I. lab claims breakthrough that could accelerate drug discovery. N Y Times [Internet]. 2020 Nov 30 [cited 2021 Nov 10]; Technology [about 3 p.]. Available from https://www.nytimes.com/2020/11/30/technology/deepmind-ai-protein-folding.html.

[3] LINK. Shuumatsu no haaremu [World's end harem]. Vol. 1. Shouno K, illustrator. Tokyo: Kabushiki-gaisha Shuueisha; 2016. ISBN: 9784088808192. Japanese.

[4] Onna-tachi no sekai [The world of women] [television episode]. Shuumatsu no haaremu [World's end harem]. Episode 1. Tokyo: Kabushiki-gaisha Sutajio Gokumi; 2021 Oct 8. Codeveloped with Kabushiki-gaisha AXsiZ. Japanese.

[5] Heaven WD. OpenAI's new language generator GPT-3 is shockingly good - and completely mindless. MIT Technology Review [Internet]. 2020 Jul 20 [cited 2021 Nov 10]; Artificial Intelligence: [about 9 p.]. Available from https:/www.technologyreview.com/2020/07/20/1005454/openai-machine-learning-languagegenerator-gpt-3-nlp/.

[6] Lauret J. GPT-3: the first artificial general intelligence? Medium [Internet]. 2020 Jul 22 [cited 2021 Nov 10]; Towards Data Science [about 10 screens]. Available from https://towardsdatascience.com/gpt-3-the-first-artificial-general-intelligence-b8d9b38557a1. 
[7] Metz C. Meet GPT-3. It has learned to code (and blog and argue). N Y Times [Internet]. 2020 Nov 24 [cited 2021 Nov 10]; Science [about 8 p.]. Available from https://www.nytimes.com/2020/11/24/science/artificial-intelligence-ai-gpt3.html.

[8] Polson N, Scott J. AIQ: how people and machines are smarter together. New York: St. Martin's Press; 2018. ISBN: 9781250182159.

[9] Kudya E. Replika: my AI friend [mobile application]. Version 9.6.5 [iOS]. San Francisco: Luka; 2021 Nov 10. Available from https://apps.apple.com/app/id1158555867.

[10] Scott K. Microsoft teams up with OpenAI to exclusively license GPT-3 language model. Official Microsoft Blog [Internet]. 2020 Sep 22 [cited 2021 Nov 10]; [about 2 p.]. Available from https://blogs.microsoft.com/blog/2020/09/22/microsoft-teams-up-with-openai-toexclusively-license-gpt-3-language-model/.

[11] Kuhn TS. The structure of scientific revolutions. $50^{\text {th }}$ anniversary ed. Chicago: University of Chicago Press; 2012. ISBN: 9780226458113.

[12] Sass H. Fritz Jahr's 1927 concept of bioethics. Kennedy Inst Ethics J 2007;17(4);279-295. doi: $10.1353 /$ ken.2008.0006.

[13] Bruner J. Making stories: law, literature, life. New York: Farrar, Straus and Girouz; 2002. [] [14] Colwell-Chanthaphonh C. Living histories: Native Americans and southwestern archaeology. Lanham (MD): AltaMira Press, 2010. ISBN: 9780759111967.

[15] Popova YB. Stories, meaning, and experience: narrativity and enaction. New York: Routledge; 2015. ISBN: 9781138499171.

[16] Jaidka M. Narratives across borders. Newcastle-upon-Tyne (UK): Cambridge Scholars Publishing; 2016. ISBN: 9781443888110.

[17] Gustafsson BE. The meaning of places through stories: a pedagogical perspective. Museum International 2011;63(1-2);63-69. doi: 10.1111/j.1468-0033.2012.01764.x. [18] Kawahara R. Soodo aato onrain [Sword art online]. Vol. 1, Ainkuraddo [Aincrad]. Tokyo: ASCII Media Works; 2009. ISBN: 9784048677608 . Co-published with Kabushiki-gaisha Kadokawa. Japanese.

[19] Kawahara R. Soodo aato onrain [Sword art online]. Vol. 3, Fearyi dansu [Fairy dance]. Tokyo: ASCII Media Works; 2009. ISBN: 9784048681933. Co-published with Kabushikigaisha Kadokawa. Japanese.

[20] Kawahara R. Soodo aato onrain [Sword art online]. Vol. 7, Mazaazu rozario [Mother's rosario]. Tokyo: ASCII Media Works; 2011. ISBN: 9784048704311 . Japanese.

[21] Kawahara R. Soodo aato onrain [Sword art online]. Vol. 9, Arishizeeshon biginingu [Alicization beginning]. Tokyo: ASCII Media Works; 2012. ISBN: 9784048862714. Japanese. [22] Kawahara R. Soodo aato onrain [Sword art online]. Vol. 10, Arishizeeshon ran'ningu [Alicization running]. Tokyo: ASCII Media Works; 2012. ISBN: 9784048866972. Japanese. [23] Kawahara R. Soodo aato onrain [Sword art online]. Vol. 18, Arishizeeshon rasutingu [Alicization lasting]. Tokyo: Kabushiki-gaisha Kadokawa; 2016. ISBN: 9784048704311. Copublished with ASCII Media Works. Japanese.

[24] Caretaker [television episode]. Star Trek: Voyager. $1^{\text {st }}$ season, pilot episode (1-2). Los Angles: Paramount Domestic Television; 1995 Jan 16.

[25] Phage [television episode]. Star Trek: Voyager. $1^{\text {st }}$ season, $5^{\text {th }}$ episode. Los Angeles: Paramount Domestic Television; 1995 Feb 6.

[26] Yui no kokoro [Yui's heart][television episode]. Soodo aato onrain [Sword art online]. Episode 12. Tokyo: Kabushiki-gaisha A-1 Pictures; 2012 Sep 23. Japanese. 
[27] Landau N. Tau [motion picture]. D’Alessandro F, director; Chestnut S, editor. Los Gatos (CA): Netflix; 2018. Netflix original film [97 min.], available from https://www.netflix.com/title/80217569?source=35 (subscription required). [28] Arishiazeeshon keikaku [Project Alicization] [television episode]. Soodo aato onrain: Arishizeeshon [Sword art online: Alicization]. Episode 6. Tokyo: Kabushiki-gaisha A-1 Pictures; 2018 Nov 11. Japanese.

[29] Arisu [Alice][television episode]. Soodo aato onrain: Arishizeeshon - war of Underworld [Sword art online: Alicization - war of Underworld]. Episode 46. Tokyo: Kabushiki-gaisha A-1 Pictures; 2020 Sep 13. Japanese.

[30] Cage D, Williams A. Detroit: become human [video game]. Cage D, writer and director. San Mateo (CA): Sony Interactive Entertainment; 2018. Available via PS4 disc. Digital download published by Quantic Dream (Paris), and available from from https://www.playstation.com/en-us/games/detroit-become-human/.

[31] Jaynes TL. Legal personhood for artificial intelligence: citizenship as the exception to the rule. AI Soc 2020;35(2);343-354. doi: 10.1007/s00146-019-00897-9.

[32] Jaynes TL. On human genome manipulation and Homo technicus: the legal treatment of non-natural human subjects. AI Eth 2021;1(3);331-345. doi: 10.1007/s43681-021-00044-5.

[33] Jaynes TL. The legal ambiguity of advanced assistive bionic prosthetics: where to define the limits of 'enhanced persons' in medical treatment. Clin Ethics 2021;16(3);171-182. doi:

$10.1177 / 1477750921994277$.

[34] Jaynes TL. Citizenship as the exception to the rule: an addendum. AI Soc 2021;36(3); 911930. doi: 10.1007/s00146-020-01105-9.

[35] Jaynes TL. The question of algorithmic personhood and being (or: on the tenuous nature of human status and humanity tests in virtual spaces - why all souls are 'necessarily' equal when considered as energy). J 2021;4(3);452-475. doi: 10.3390/j4030035.

[36] Turing AM. I. - computing machinery and intelligence. Mind 1950;LIX(236);433-460. doi: 10.1093/mind/LIX.236.433.

[37] Johansson L. The functional morality of robots. Int J Technoethics 2010;1(4);65-73. doi: $10.4018 /$ jte. 2010100105 .

[38] Glenn LM. What is a person? In: Bess M, Pasulka DW, editors. Posthumanism: the future of Homo sapiens. $1^{\text {st }}$ ed. Farmington Hills (MI): Macmillan Reference USA; 2018. p. 229-246.

ISBN: 9780028664477.

[39] Dowell R. Fundamental protections for non-biological intelligences (or: how we learn to stop worrying and love our robot brethren). Minn J Law Sci Technol 2018;19(1);306-336.

Available from https://scholarship.law.umn.edu/mjlst/vol19/iss1/6.

[40] Lin P, Abney K, Jenkins R, editors. Robot ethics 2.0: from autonomous cars to artificial intelligence. New York: Oxford University Press; 2017. ISBN: 9780190652951.

[41] Coeckelbergh M. AI ethics. Cambridge (MA): The MIT Press; 2020. ISBN:

9780262538190.

[42] Kerns M, Roth A. The ethical algorithm: the science of socially aware algorithm design. New York: Oxford University Press; 2020. ISBN: 9780190948207.

[43] Harris J, Anthis JR. The moral consideration of artificial entities: a literature review. Sci

Eng Ethics 2021;27(4): [94 p.]. doi: 10.1007/s11948-021-00331-8.

[44] O'Riordan T, Cameron J, editors. Interpreting the Precautionary Principle. London:

Earthscan Publications; 1994. ISBN: 9781853832000. 
[45] Schick A. Whereto speculative bioethics? Technological visions and future simulations in a science fiction culture. Med Humanit 2016;42(4);225-231. doi: 10.1136/medhum-2016-010951. [46] Blosch M, Fenn J. Understanding Gartner's hype cycles [Internet]. Stamford (CT): Gartner; 2018 [cited 2021 Nov 10]. Available from https://www.gartner.com/en/documents/3887767. [47] Chapman, AR. Brain models in a dish: ethical issues in developing brain organoids. AJOB Neurosci 2019;10(3);113-115. doi: 10.1080/21507740.2019.1632963.

[48] Paul K. Dozens sue Amazon's Ring after camera hack leads to threats and racial slurs. The Guardian, US ed. [Internet]. 2020 Dec 23 [cited 2021 Nov 10]; [about 5 p.]. Available from https://www.theguardian.com/technology/2020/dec/23/amazon-ring-camera-hack-lawsuitthreats.

[49] Kawahara R. Soodo aato onrain [Sword art online]. Vol. 2, Ainkuraddo [Aincrad]. Tokyo: ASCII Media Works; 2009. ISBN: 9784048679350 . Co-published with Kabushiki-gaisha Kadokawa. Japanese. 